\title{
ANÁLISE ECONOMÉTRICA DOS DISPÊNDIOS EM PESQUISA \& DESENVOLVIMENTO (P\&D) NO BRASIL
}

\author{
Michel Angelo Constantino Oliveira \\ Doutor em Economia pela Universidade Católica de Brasília - UCB \\ Professor da Universidade Católica Dom Bosco - UCDB \\ michelangelo111@gmail.com (Brasil)
}

\section{Dany Rafael Fonseca Mendes}

Mestrado em Direito pela Universidade Católica de Brasília - UCB

Professor do Centro Universitário de Brasília - UniCEUB

rafael.dany@gmail.com (Brasil)

\section{Tito Belchior Silva Moreira}

Doutorado em Economia pela Universidade de Brasília - UNB

Professor/pesquisador do departamento de economia da Universidade Católica de Brasília - UCB tito@ucb.br (Brasil)

\section{George Henrique de Moura Cunha}

Doutorado em Economia pela Universidade de Brasília - UNB

Diretor do Curso de Graduação da Universidade Católica de Brasília - UCB

georgec@ucb.br (Brasil)

\section{RESUMO}

Essa pesquisa teve como objetivo principal analisar o panorama dos dispêndios em P\&D no Brasil e, mais especificamente, avaliar o impacto desses gastos nos pedidos de patentes nacionais, além do impacto no Produto Interno Bruto (PIB) do País. As séries analisadas mostram a evolução agregada dos dispêndios em P\&D para o período analisado. Quando desagregado por grande região, os dados mostram que o Sudeste e o Sul se destacam no pedido e na concessão de patentes pelo Instituto Nacional de Propriedade Intelectual (INPI ${ }^{1}$ ). Os resultados das estimações dos sete modelos econométricos propostos confirmam a importância dos dispêndios públicos e privados no crescimento do PIB e no aumento da quantidade de patentes depositadas no INPI. Outro resultado das estimações este trabalho demostram que esses dispêndios apresentam comportamento Random-Walk (passeio aleatório ${ }^{2}$ ).

Palavras-chave: Inovação; P\&D; Patentes; Econometria; Random-Walk.

${ }^{1}$ Criado pela Lei no 5648, de 11 de dezembro de 1970 (BRASIL), o Instituto Nacional da Propriedade Industrial é a autarquia federal responsável pelo aperfeiçoamento, disseminação e gestão do sistema brasileiro de concessão e garantia de direitos de propriedade intelectual para a indústria. Entre os serviços do INPI, estão os registros de marcas, desenhos industriais, indicações geográficas, programas de computador e topografias de circuitos, as concessões de patentes e as averbações de contratos de franquia e das distintas modalidades de transferência de tecnologia. Na estrutura da Administração Pública, o INPI está vinculado ao Ministério do Desenvolvimento, Indústria e Comércio Exterior (MDIC), com sede e foro no Distrito Federal (Instituto Nacional de Propriedade Industrial - INPI, 2012).

${ }^{2}$ Um passeio aleatório é uma formalização matemático de um caminho que consiste de uma sucessão de etapas aleatórias, e o termo foi introduzido pela primeira vez por Karl Pearson em "The Problem of the Random Walk" (1905). 


\section{INTRODUÇÃO}

A literatura que explora a economia da inovação - notadamente Griliches (1990) e Associação Nacional de Pesquisa e Desenvolvimento das Empresas Inovadoras - ANPEI (2014) - tem afirmado que os dispêndios com P\&D são insumos para a produção de conhecimentos novos que, em algum momento, poderão, ou não, traduzir-se em inovações. Embora este trabalho esteja lastreado no conceito de inovação adotado pela edição mais atual do Manual de Oslo (Organização para a Cooperação e Desenvolvimento Econômico - OCDE, 2005), em consonância com a evolução conceitual apresentada por Mendes, Oliveira \& Pinheiro (2013), a medição relativa à inovação ficou restrita às avaliações de investimentos em $\mathrm{P} \& \mathrm{D}$ e depósitos de patentes.

A inovação é um dos principais determinantes do desenvolvimento tecnológico e socioeconômico dos países, e, mesmo não havendo uma relação direta de causa e efeito entre essas variáveis, aqueles Estados que possuem políticas públicas voltadas para inovação tecnológica, normalmente, são nações mais ricas, possuem um parque industrial mais avançado e apresentam menos desigualdade social.

Um dos principais fatores a influenciar ativamente o processo de inovação tecnológica é representado pelos gastos em P\&D. Segundo o manual da OECD (2005), pesquisa e desenvolvimento compreende o trabalho criativo realizado em uma base sistemática com a finalidade de aumentar o estoque de conhecimento existente, incluindo conhecimento científico e tecnológico, assim como o uso desse conhecimento para novas aplicações.

Com intuito de comprovar a visão schumpteriana que influenciara a definição da OCDE (Mendes, Oliveira, \& Pinheiro, Política Nacional de Ciência, Tecnologia e Inovação: Avaliação do Marco Regulatório e seus Impactos nos Indicadores de Inovação, 2013), a presente pesquisa empírica tem como foco a análise dos dispêndios em P\&D no Brasil entre 2000 e 2011. Além disso, o objetivo se estende à avaliação do impacto desses dispêndios nos pedidos de patentes nacionais e o impacto no Produto Interno Bruto brasileiro, por meio da análise econométrica de sete modelos aqui propostos.

Este trabalho está dividido nesta introdução (seção 1), na apresentação de conceitos e da importância dos diferentes sistemas de apropriação do conhecimento (seção 2), no panorama das variáveis analisadas (seção 3), na descrição da metodologia de pesquisa e da modelagem teórica e econométrica (seção 4), na apresentação e discussão dos resultados empíricos (seção 5) e, por fim, nas considerações finais (seção 6).

Revista de Administração e Inovação, São Paulo, v. 12, n.3 p. 268-286, jul./set. 2015. 
Como uma das metodologias de aproximação dos dados adotada por este trabalho está diretamente relacionada a um método tradicional de apropriação das externalidades positivas advindas da inovação, a carta-patente, é importante apresentar um breve relato sobre a evolução dos conceitos de apropriabilidade e dos diferentes sistemas de apropriação do conhecimento.

\section{RELEVÂNCIA ECONÔMICA DA APROPRIAÇÃO}

Antes de partir para a relevância econômica da apropriabilidade, é importante esclarecer que, para o Direito, as metodologias de apropriação consideradas pela Economia não se encaixam no conceito de apropriabilidade do Direito, o qual, de acordo com Mendes (2014), dá-se pelo estabelecimento da propriedade sobre determinado bem. Ainda conforme o autor, para estabelecer o que é, ou deixa de ser, um direito de propriedade, basta submeter os direitos que um detentor tem sobre determinada coisa a uma análise de subsunção aos elementos formais do art. 1.228 da Lei $\mathrm{n}^{\circ} 10.406$, de 10 de janeiro de 2002 (BRASIL). Resumidamente, se o detentor da coisa tem sobre esta todos os direitos elencados no referido artigo do Código Civil, trata-se de um direito de propriedade. Contudo, posto que se tratasse de um esclarecimento necessário, essa discussão entre conceitos da Economia versus conceituação do Direito não será objeto do presente estudo.

De volta à evolução dos conceitos de apropriabilidade e dos diferentes sistemas de apropriação do conhecimento, a literatura vem se aprofundando no entendimento sobre a análise da importância da apropriação dos conhecimentos e da inovação tecnológica no desempenho econômico, especialmente no âmbito empresarial. De acordo com Hanel (2008), a conclusão bem sucedida de um processo de inovação, per si, não é condição suficiente para que o inovador obtenha benefícios esperados a partir de sua criação. Os criadores, especialmente os empresários, também precisam ser capazes de se apropriar desses benefícios, evitando, inclusive, que os seus concorrentes venham imitá-los. O método mais formal à consecução desse tipo de proteção é delimitação de direitos de propriedade intelectual, mas há outras estratégias, como é o caso do tempo de liderança no mercado (lead time) ou dos segredos industrial e de negócios.

Os métodos de apropriação das externalidades positivas oriundas da inovação estão amarrados aos setores e às especificidades tecnológicas relativas a estes setores da economia, assim como também dependem do comportamento estratégico das empresas. Em geral, grandes empresas, com departamentos de P\&D bem dimensionados, preferem usar as patentes como método de apropriação. A importância dessa metodologia de apropriação, por meio de pedidos de patentes, segundo Arundel et al

Revista de Administração e Inovação, São Paulo, v. 12, n.3 p. 268-286, jul./set. 2015. 
(1998), aumenta de acordo com a relevância dos mercados globais, desempenhando um papel importante na capacidade de entrada das firmas em mercados estrangeiros. Contudo, segundo Levin et al (1987), as patentes não são o mecanismo mais frequente de apropriação. Em vez disso, o segredo industrial e as vantagens do lead time são as estratégias mais utilizadas pelos empresários em geral, embora essa constatação não possa ser aplicada a todos os setores ou tipos de inovação. Numa análise geral, os inovadores de produtos utilizam mais frequentemente as patentes como método de apropriação do que os inovadores do processo. Na mesma linha, alguns setores específicos, como o farmacêutico, por exemplo, usam patentes com mais frequência para garantir seus retornos de investimentos tecnológicos.

Noutra linha de abordagem, os custos relativos à entrada e manutenção de uma empresa no sistema de proteção patentária estão entre os principais motivos pelos quais as firmas têm evitado essa estratégia de apropriação das externalidades positivas oriundas do conhecimento e da inovação. Por isso, as empresas com restrições financeiras tendem a preferir outros métodos de apropriação que não os direitos de propriedade intelectual, uma vez que, em análise marginal, os benefícios decorrentes da exclusão de concorrentes por meio de direitos de propriedade intelectual devem, necessariamente, compensar esses custos, mesmo quando esses benefícios são comparados a outras opções disponíveis. Ainda nessa linha de avaliação entre as possibilidades de métodos de apropriação, em contraste com os direitos de propriedade intelectual (patentes, por exemplo), que têm vigência pré-definida, o segredo industrial pode proteger uma criação indefinidamente no tempo. Este tipo de método também é aplicável a uma gama muito mais ampla de criações, indo além das patentes, já que, no caso do segredo, não há qualquer restrição relativa à matéria patenteável, no exemplo das patentes. Ainda assim, os segredos industrial e de negócio também apresentam altos custos, incluindo aqueles referentes aos acordos de confidencialidade, por exemplo.

Quando se trata do tempo de liderança sobre os concorrentes, este tipo de estratégia de apropriação costuma prevalecer, mesmo sem o uso formal de direitos de propriedade intelectual. Nesse sentido, Dosi et al (1994) apontou que a difusão de inovações não é instantânea e depende da heterogeneidade entre os agentes, da infraestrutura adequada para a assimilação tecnológica, e do tempo para aprender a dominar novas tecnologias.

Demonstrada a importância econômica das estratégias de apropriação da inovação, tanto no âmbito privado quanto na esfera pública, à frente, para conhecer o comportamento das séries de tempo de cada variável relacionada com a abordagem de $\mathrm{P} \& \mathrm{D}$ a próxima seção descreve as informações mais relevantes em gráficos que representam os movimentos passados dos agregados entre 2000 e 2011 na economia brasileira.

Revista de Administração e Inovação, São Paulo, v. 12, n.3 p. 268-286, jul./set. 2015. 


\section{PANORAMA DO DISPÊNDIO EM P\&D NO BRASIL}

O comportamento das séries de dados do MCTI (2014) entre 2000 e 2011 mostra a evolução da economia da inovação brasileira, partindo do panorama dos dispêndios em P\&D e chegando à construção de pedidos de patentes. Os dados para análise foram organizados na

Tabela 1 e servem à visualização do panorama dos dispêndios em $\mathrm{P} \& \mathrm{D}$, além de expor as variáveis correlacionadas com essa abordagem. Mais à frente, após a exposição desse panorama, as variáveis apresentadas na

Tabela 1serão utilizadas para a estimação econométrica que se seguirá (seções 4.1 e 5).

\section{Tabela 1}

Dados Agregados, Brasil, 2000-2011

\begin{tabular}{|c|c|c|c|c|c|c|c|c|c|}
\hline Ano & $\begin{array}{c}\text { PIB em } \\
\text { milhões R\$ } \\
\text { de 2012 }\end{array}$ & $\begin{array}{c}\text { Patentes } \\
\text { concedidas } \\
\text { por } \\
\text { residentes }\end{array}$ & $\begin{array}{c}\text { Pedido } \\
\text { de } \\
\text { Patentes } \\
\text { Total }\end{array}$ & $\begin{array}{c}\text { Pedido } \\
\text { Patentes } \\
\text { por } \\
\text { Residentes }\end{array}$ & $\begin{array}{c}\text { Pedido de } \\
\text { Patentes } \\
\text { por não } \\
\text { residentes }\end{array}$ & $\begin{array}{c}\text { Gasto } \\
\text { Total } \\
\text { com } \\
\text { P\&D }\end{array}$ & $\begin{array}{c}\text { Gasto } \\
\text { Público }\end{array}$ & $\begin{array}{c}\text { Gasto } \\
\text { Privado }\end{array}$ & $\begin{array}{c}\text { em } \\
\text { relação ao } \\
\text { PIB }\end{array}$ \\
\hline 2000 & $2.978 .755,2$ & 1.071 & 20.639 & 6.448 & 14.191 & $28.792,2$ & $15.567,9$ & $13.224,3$ & 1,02 \\
\hline 2001 & $3.017 .869,8$ & 704 & 21.474 & 6.968 & 14.506 & $29.876,4$ & $16.385,3$ & $13.491,1$ & 1,04 \\
\hline 2002 & $3.098 .087,6$ & 690 & 20.317 & 7.053 & 13.264 & $28.959,5$ & $15.444,3$ & $13.515,2$ & 0,98 \\
\hline 2003 & $3.133 .610,9$ & 834 & 20.169 & 7.563 & 12.606 & $28.494,3$ & $15.443,9$ & $13.050,4$ & 0,96 \\
\hline 2004 & $3.312 .611,9$ & 533 & 20.430 & 7.701 & 12.729 & $28.285,5$ & $15.119,8$ & $13.165,7$ & 0,90 \\
\hline 2005 & $3.417 .279,6$ & 605 & 21.850 & 7.355 & 14.495 & $31.508,4$ & $15.668,0$ & $15.840,4$ & 0,97 \\
\hline 2006 & $3.552 .502,6$ & 498 & 23.144 & 7.195 & 15.949 & $33.992,5$ & $16.951,8$ & $17.040,6$ & 1,01 \\
\hline 2007 & $3.768 .900,1$ & 387 & 24.841 & 7.327 & 17.514 & $39.180,3$ & $20.413,0$ & $18.767,3$ & 1,10 \\
\hline 2008 & $3.963 .812,4$ & 529 & 26.681 & 7.736 & 18.945 & $41.928,1$ & $21.940,1$ & $19.988,0$ & 1,11 \\
\hline 2009 & $3.950 .742,7$ & 687 & 25.967 & 7.766 & 18.201 & $43.733,5$ & $22.573,1$ & $21.160,4$ & 1,17 \\
\hline 2010 & $4.248 .379,3$ & 667 & 28.141 & 7.286 & 20.855 & $45.192,1$ & $23.039,2$ & $22.152,9$ & 1,12 \\
\hline 2011 & $4.364 .479,2$ & 725 & 31.767 & 7.766 & 24.001 & $49.973,7$ & $26.382,6$ & $23.591,1$ & 1,21 \\
\hline
\end{tabular}

Fonte: MCTI (2014).

3 As organizações adotadas na análise foram as empresas privadas e os órgãos públicos que de forma agregada usam seus recursos para o resultado fim, que é a inovação. Analisar dispêndios de empresas de empresas privadas de forma individual e também por setores, não é possível pela falta de informações/dados, que dependem de forma de desagregação dos dados e informações confidenciais das próprias empresas. 
É possível perceber que em todas as séries há aumentos significativos nos valores e quantidades relacionadas com a pesquisa e desenvolvimento ao longo do tempo.

Para analisar os resultados mais relevantes para os objetivos deste trabalho, algumas séries foram organizadas em gráficos para demonstrar a evolução das séries temporais ${ }^{4}$. Os investimentos nacionais em ciência e tecnologia comparados ao montante do PIB nacional são apresentados na Figura 1.

\section{Figura 1}

Dispêndio nacional em C\&T em relação ao PIB por setor, 2000-2011

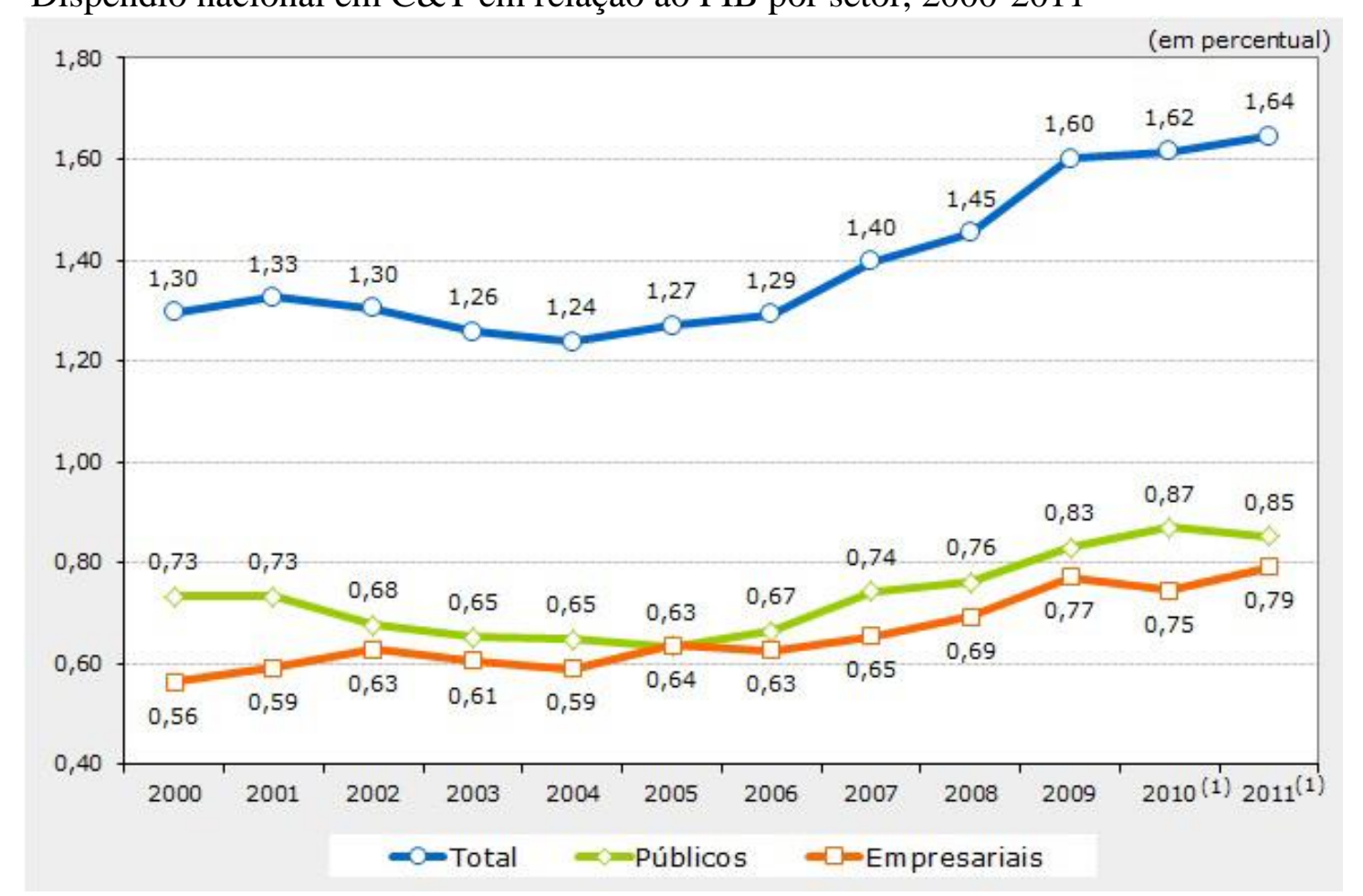

Fonte(s): Dispêndios federais: Sistema Integrado de Administração Financeira do Governo Federal (Siafi). Extração especial realizada pelo Serviço Federal de Processamento de Dados - Serpro; Dispêndios estaduais: Balanços Gerais dos Estados e levantamentos realizados pelas Secretarias Estaduais de Ciência e Tecnologia ou instituições afins; e Dispêndios empresariais: Pesquisa de Inovação Tecnológica - Pintec/IBGE e levantamento realizado pelas empresas estatais federais, a pedido do MCTI.

Elaboração: Coordenação-Geral de Indicadores (CGIN)- ASCAV/SEXEC - Ministério da Ciência e Tecnologia, 2010.

A Figura 1, reconfirmando as hipóteses levantadas por Mendes, Oliveira \& Pinheiro em "Política Nacional de Ciência, Tecnologia e Inovação: Avaliação do Marco Regulatório e seus Impactos nos Indicadores de Inovação" (2013), apresenta uma evolução visual a partir do marco legal

\footnotetext{
${ }^{4}$ Uma série temporal é uma coleção de observações feitas sequencialmente ao longo do tempo. Em modelos de regressão linear com dados em séries temporais a ordem dos dados é fundamental. Mais detalhes em HAYASHI, Fumio. Econometrics (Hayashi, 2000).
} 
de incentivo à inovação - (Lei da Inovação - Lei no 10.973, de 2 de dezembro 2004) e (Lei do Bem Lei $\mathrm{n}^{\circ}$ 11.196, de 21 de novembro de 2005) - instituído há aproximadamente uma década. Os dispêndios nacionais em ciência e tecnologia em relação percentual ao produto interno bruto entre 2000 e 2011 passaram de 1,30\% para 1,64\% respectivamente.

Partindo dos investimentos em C\&T para a análise de $\mathrm{P} \& \mathrm{D}$, mais afeta ao setor produtivo privado, em termos de valores, houve um aumento interessante no dispêndio nacional em pesquisa e desenvolvimento no mesmo período, saindo de 28.792 milhões de reais, no ano 2000, para 49.974 milhões, onze anos mais tarde, conforme exposto na

Figura 2. Mais uma constatação da importância que o marco legal da inovação vem exercendo nesse tipo de dispêndio (Mendes, Oliveira, \& Pinheiro, Política Nacional de Ciência, Tecnologia e Inovação: Avaliação do Marco Regulatório e seus Impactos nos Indicadores de Inovação, 2013).

\section{Figura 2}

Dispêndio nacional em P\&D (em valores de 2011) total e por setor

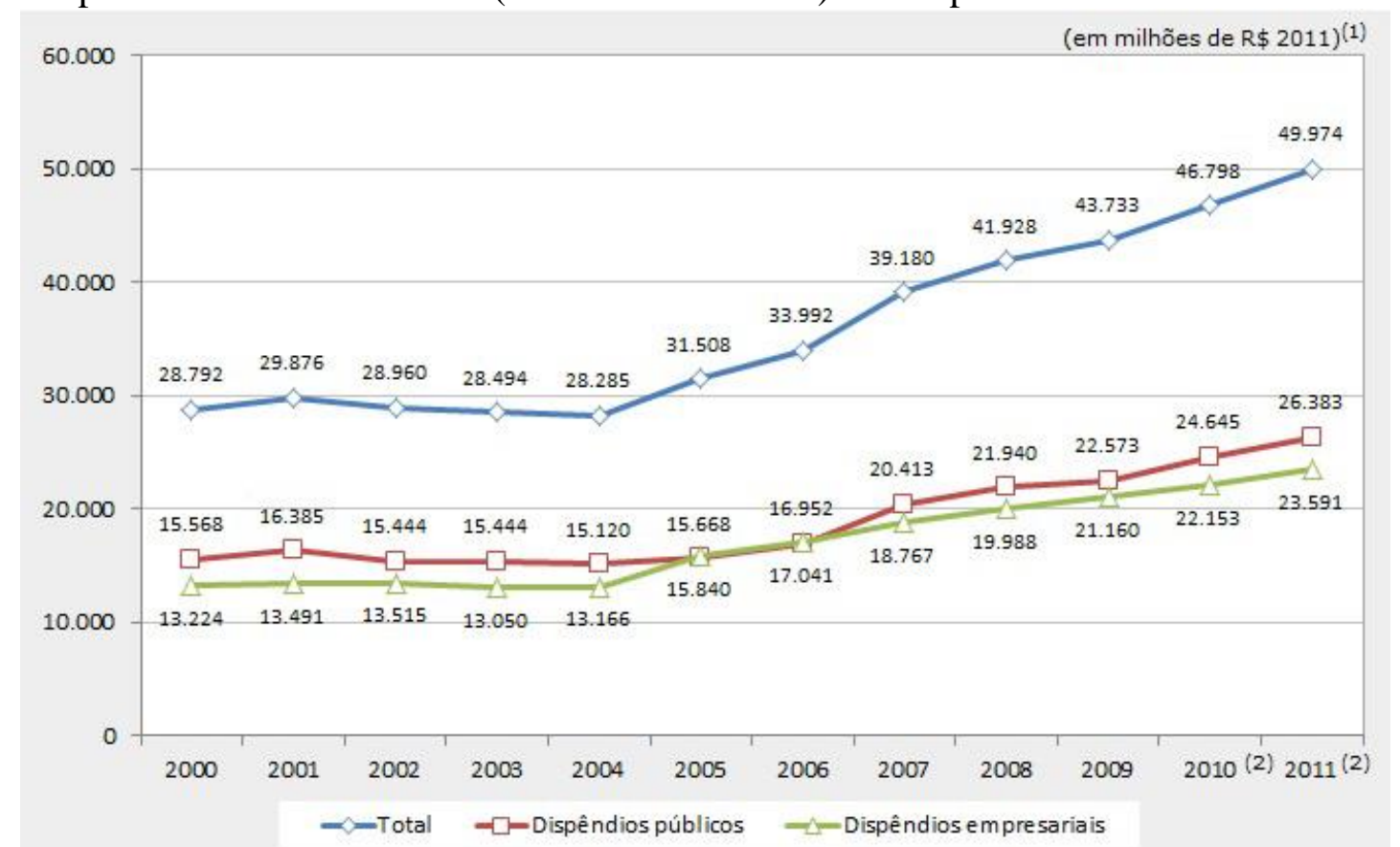

Fonte(s): Dispêndios federais: Sistema Integrado de Administração Financeira do Governo Federal (Siafi). Extração especial realizada pelo Serviço Federal de Processamento de Dados - Serpro; Dispêndios estaduais: Balanços Gerais dos Estados e levantamentos realizados pelas Secretarias Estaduais de Ciência e Tecnologia ou instituições afins; e Dispêndios empresariais: Pesquisa de Inovação Tecnológica - Pintec/IBGE e levantamento realizado pelas empresas estatais federais, a pedido do MCTI.

Elaboração: Coordenação-Geral de Indicadores (CGIN)- ASCAV/SEXEC - Ministério da Ciência e Tecnologia, 2010.

Para conhecer os setores econômicos que têm recebido maior e menor aporte de recursos para pesquisa e desenvolvimento, podemos acompanhar a distribuição desses recursos na Figura 3. 


\section{Figura 3}

Distribuição percentual dos dispêndios públicos em P\&D, por objetivo socioeconômico (2011).

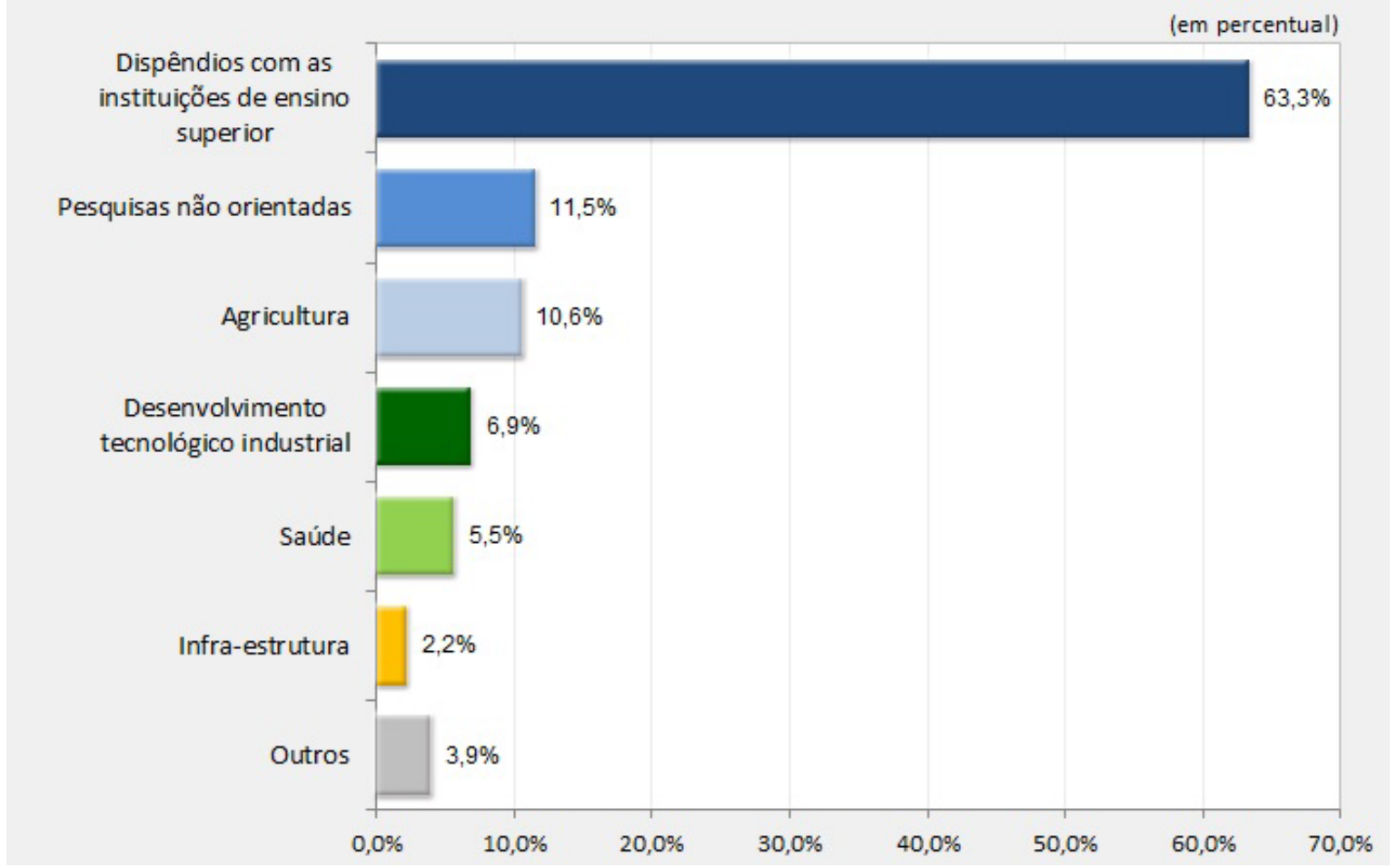

Fonte: IBGE, Siafi, 2014.

A Figura 3 deixa clara a importância das universidades no aporte e aplicação dos recursos nacionais públicos destinados à $\mathrm{P} \& \mathrm{D}$, apresentando uma dimensão de 63,3\% de todos os gastos públicos. É importante salientar o crescimento na pesquisa e desenvolvimento para o setor agrícola, uma vez que o Brasil depende do aumento de produtividade desse setor para suprir a demanda nacional e parte da demanda mundial de alimentos.

Até o momento, apenas o lado do input foi analisado, ou seja, a entrada de recursos financeiros para aplicação em atividade de pesquisa e desenvolvimento. Um dos pontos a avaliar é o output, ou seja, a saída ou o produto desse investimento. Uma das proxys mais utilizadas para medir o desempenho em P\&D refere-se aos pedidos de patentes depositados no INPI por residentes. 


\section{Figura 4}

Pedidos de patentes depositados no INPI, por residentes, por grandes regiões, 2000-2012.

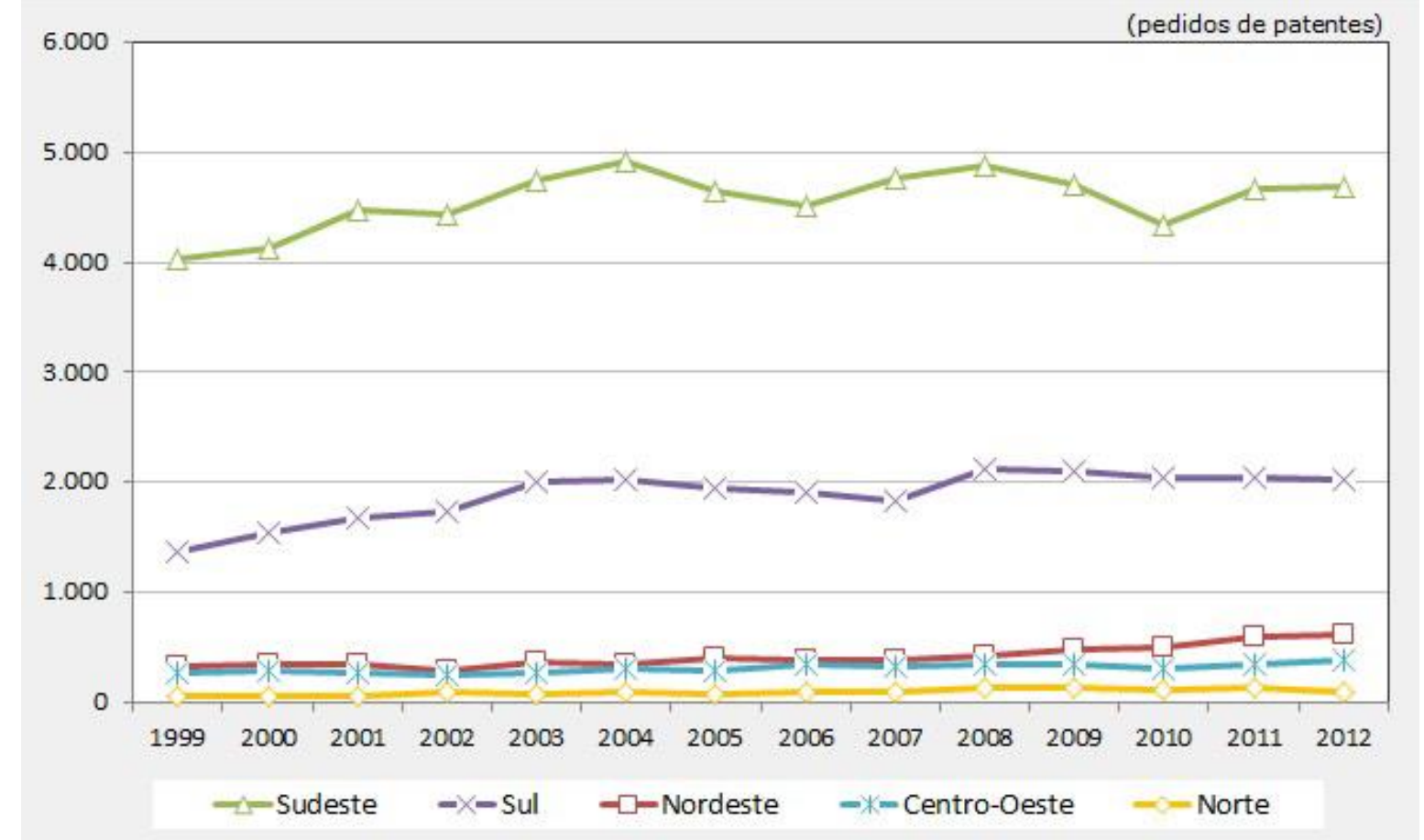

Fonte: INPI (2012).

As quantidades de patentes depositadas no INPI cresceram entre 2000 e 2012 em todas as grandes regiões brasileiras, com destaque para as regiões Sul e Sudeste, que apresentam maiores números de depósitos e maior crescimento ao longo do tempo. As evidências da Figura 4 mostram que, quando analisados a distribuição espacial do território brasileiro, os recursos nacionais estão distribuídos de maneira ineficiente.

Para avaliar o efetivo retorno dos dispêndios em P\&D na criação de patentes, é possível analisar a quantidade de patentes concedidas pelo INPI no mesmo período. É importante destacar que o INPI tem suas limitações de recursos, e isso pode ser um fator de atraso na concessão de patentes no Brasil, uma vez que alguns trabalhos mostram que existem concessões após 10 anos do pedido inicial da patente. Esse problema, contudo, não será discutido no presente trabalho. 


\section{Figura 5}

Patentes concedidas no INPI, por residentes, por grandes regiões, 1999-2011.

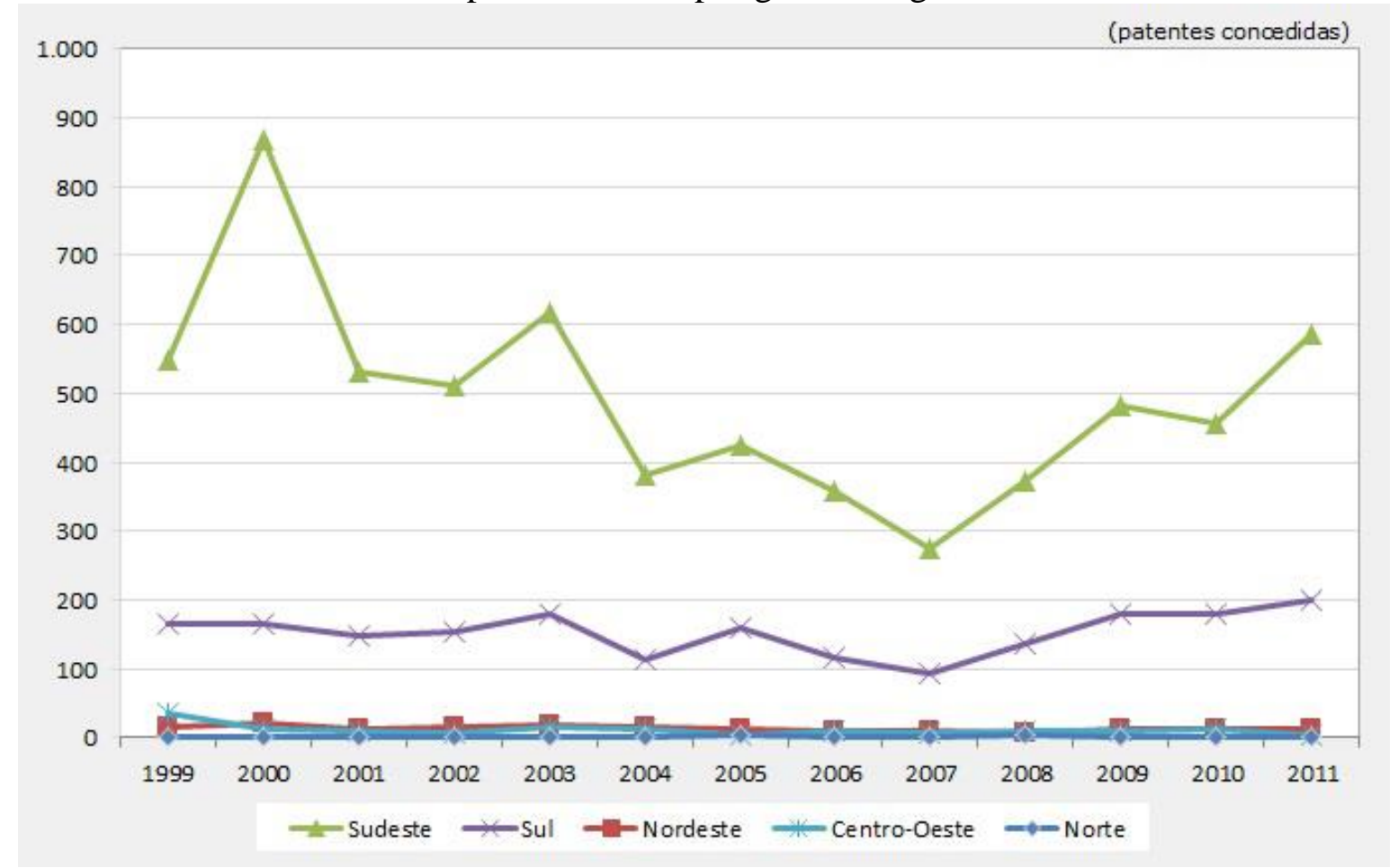

Fonte: INPI (2012).

Conforme interpretação da Figura 5, as regiões Sul e Sudeste continuam se destacando pela quantidade de patentes concedidas pelo INPI, e as demais regiões exercem pouco efeito sobre essa proxy de inovação. Na região Sudeste há várias variações no desfecho das patentes entre 1999-2011, e na região Sul o comportamento é mais linear, com evolução positiva.

Após essa análise sobre as séries de tempo, na próxima seção serão discutidos os modelos teóricos que vão avaliar estatisticamente o efeito dos dispêndios em pesquisa e desenvolvimento, utilizando formas robustas de entender os resultados esperados.

\section{METODOLOGIA}

Os testes empíricos partiram de algumas variações de modelos econométricos, e as principais diferenças entre estes aparecem no formato e na posição das variáveis dependentes e independentes, 
além de utilizar estimação por Mínimos Quadrados Ordinários $\left(\mathrm{OLS}^{5}\right)$ padrão, com mudanças e em primeira diferença (First Difference ${ }^{6}$ ), com intuito de ampliar a análise e seus efeitos.

Os dados utilizados nesta pesquisa são referentes ao período de 2000 a 2012 e foram retirados do Ministério de Ciências Tecnologia e Inovação (MCTI), do Sistema Integrado de Administração Financeira (SIAFI) do Governo Federal, do Instituto Brasileiro de Geografia Estatística (IBGE), do INPI e dos SIAFI estaduais.

A abordagem econométrica proposta já foi exaustivamente utilizada na literatura específica, sendo resultado de intensos testes de robustez e comprovação estatística. As séries temporais utilizadas para a análise econométrica é um conjunto de observações de uma determinada variável ou de várias variáveis ao longo do tempo. Os dados aqui utilizados foram analisados a partir das características das séries de interesse e também do comportamento da própria série.

Nessa pesquisa não há objetivo de discutir a metodologia, mas tão-somente de aplicar e analisar seus resultados.

\subsection{Modelos teóricos}

Com o objetivo de analisar o impacto dos dispêndios nos pedidos de patentes nacionais no PIB do País, essa seção tem como objetivo introduzir uma discussão sobre os modelos econométricos elaborados para medir cada parâmetro de interesse.

Para estimar a contribuição dos dispêndios públicos e privados com P\&D entre 2000 e 2011 e avaliar esse incremento no PIB nacional, foram propostos três modelos econométricos, o primeiro é:

\footnotetext{
${ }^{5}$ O Método dos Quadrados Mínimos, ou Quadrados Mínimos Ordinários (MQO) ou OLS (do inglês Ordinary Least Squares) é uma técnica de otimização matemática que procura encontrar o melhor ajuste para um conjunto de dados tentando minimizar a soma dos quadrados das diferenças entre o valor estimado e os dados observados (tais diferenças são chamadas resíduos), detalhes em “Econometrics” (Hayashi, 2000).

${ }^{6}$ O estimador de primeira diferença (FD) é uma abordagem utilizada para resolver o problema de variáveis omitidas em econometria e estatística. O estimador é obtido pela execução de uma estimativa OLS reunidas para uma regressão, ver maiores explicações em "Econometric Analysis of Cross-Section and Panel Data" (Woodridge, 2001).
}

Revista de Administração e Inovação, São Paulo, v. 12, n.3 p. 268-286, jul./set. 2015. 


\section{Modelo 1}

$Y_{t}=\beta P D_{t}+\varepsilon_{t}$

,onde $Y_{t}$ é o PIB nacional anual, medido em milhões de reais, para o ano de 2012, e $P D_{t}$ é o dispêndio em P\&D anual, também medido em milhões de reais, e $\varepsilon_{t}$ é o termo de erro ${ }^{7}$.

Para contornar o problema de raiz unitária ${ }^{8}$ de séries temporais foi realizado um teste de Dickey-Fuller $\left(\mathrm{DF}^{9}\right)$ aumentado, e a variável dependente usada no Modelo 1, o PIB, foi transformada em uma razão da $\frac{P D_{t}}{Y_{t}}$ P\&D sobre o PIB, estimadas por OLS (Modelo 2).

\section{Modelo 2}

$$
\frac{P D_{t}}{Y_{t}}=\beta P D_{t}+\varepsilon_{t}
$$

Para uma análise mais completa, propôs-se também a utilização do modelo em diferenças (Modelo 3), estimando em primeira diferença $\Delta \mathrm{o}$ PIB $\Delta Y_{t-1}$ e a $\mathrm{P} \& \mathrm{D} \Delta P D_{t-1}$ :

\section{Modelo 3}

$$
\Delta Y_{t-1}=\beta \Delta P D_{t-1}+\varepsilon_{t}
$$

Os modelos 1, 2 e 3 formam um conjunto para avaliar o impacto direto da P\&D no Produto Interno Bruto nacional no período de 2000 a 2011. A partir dos próximos modelos, verifica-se o efeito em uma nova variável dependente.

\footnotetext{
${ }^{7}$ O termo de erro equivale à distância vertical entre os pontos observados e os pontos correspondentes sobre a reta de regressão, mais detalhes em “Econometria Básica” (Gujarati, 2000).

${ }^{8}$ A unidade de raiz é uma característica dos processos que evoluem ao longo do tempo e que podem causar problemas na inferência estatística, se não for tratada adequadamente. Um processo estocástico linear tem uma raiz unitária se 1 é raiz da equação característica do processo (Gujarati, 2000).

${ }^{9}$ Em estatística, o teste de Dickey-Fuller foi criado para verificar se um modelo autorregressivo tem ou não raiz unitária. O teste foi sugerido por Dickey e Fuller (daí o nome) em 1979 no artigo intitulado "Distribution of the Estimators for Autoregressive Time Series with A Unit Root" publicado no periódico "Journal of the American Statistical Association".
} 
Analisando agora o impacto do dispêndio público e privado em pesquisa e desenvolvido entre 2000 e 2011 para o incremento na criação de patentes, o modelo econométrico utilizado inicialmente foi:

\section{Modelo 4}

$$
X_{t}=\theta P D_{t}+\varepsilon_{t}
$$

onde $X_{t}$ é a quantidade total de pedidos de patentes registradas anualmente entre 2000 e 2011 no INPI, $\theta$ é o coeficiente a estimar e $P D_{t}$ é a variável do dispêndio em pesquisa e desenvolvimento, além do $\varepsilon_{t}$, que é o termo de erro.

Os mesmos procedimentos de estimação anteriores são utilizados no Modelo 4, estimando por OLS com output de patentes. Para o próximo (Modelo 5), a variável depende é transformada, como no Modelo 2, tornando-se $\frac{P D_{t}}{X_{t}}$. Completo, o Modelo 5 é descrito da seguinte maneira:

$$
\begin{aligned}
& \text { Modelo } 5 \\
& \frac{P D_{t}}{X_{t}}=\theta P D_{t}+\varepsilon_{t}
\end{aligned}
$$

A estimação em primeira diferença proposta no Modelo 3 também é proposta no Modelo 6 abaixo, utilizando as variáveis defasadas em primeira diferença $\triangle X_{t-1}$ e $\triangle P D_{t-1}$, ficando:

\section{Modelo 6}

$$
\Delta X_{t-1}=\beta \Delta P D_{t-1}+\varepsilon_{t}
$$

Do Modelo 1 ao Modelo 6, foram estimados os impactos de variáveis independentes. No próximo modelo, o objetivo passa a ser a verificação de uma variável $\left(P D_{t}\right)$ sobre si mesma no passado, ou seja, defasada - resultado de interesse para este trabalho. Na literatura econométrica esse comportamento é conhecido como passeio aleatório, ou seja, toda variação sucessiva em $P D_{t}$ é gerada 
de uma distribuição de probabilidade com média igual a zero, ou seja, $P D_{t}$ é determinado pelo $P D_{t-1}$,

conforme modelo que segue:

\section{Modelo 7}

$$
P D_{t}=\alpha P D_{t-1}+\varepsilon_{t}
$$

Após a criação e proposta desses sete modelos, as estimações foram realizadas e seus resultados serão discutidos na próxima seção.

\section{RESULTADOS EMPÍRICOS}

Foram estimados todos os modelos teóricos propostos, com objetivo de responder as questões pertinentes aos efeitos dos dispêndios públicos e privados com P\&D no Brasil durante o período de 2000 a 2011.

Numa primeira abordagem, foi analisado qual seria é o efeito dos dispêndios nacionais em P\&D no Produto Interno Bruto brasileiro. Foi estimado por OLS o padrão, Modelo 1, sem nenhuma mudança nas variáveis, no Modelo 2 a variável dependente é uma razão entre P\&D e PIB, e, no Modelo 3 foi realizada a estimação em primeira diferença.

\section{Os resultados da}

Tabela 2 mostram que, em todos os modelos aqui propostos, os efeitos, ou seja, os coeficientes apresentam sinal esperado positivo. Nos modelos 1 e 2, os resultados são altamente significativos, já no Modelo 3, em função do p-valor estatisticamente insignificante, demonstrando que o modelo em diferenças pode não ser adequado ao caso.

\section{Tabela 2}

Resultado Impacto da P\&D no PIB (2000-2011)

\begin{tabular}{|c|c|c|c|}
\hline & Modelo 1 & Modelo 2 & Modelo 3 \\
\cline { 2 - 4 } & OLS1 & OLS2 & FD \\
\hline Coeficiente & 60,57051 & $1.04 \mathrm{e}-07$ & 13,33963 \\
\hline $\mathrm{p}$-valor & {$[0.000]$} & {$[0.000]$} & {$[0.377]$} \\
\hline
\end{tabular}

Fonte: Elaboração própria. 
No caso dos demais modelos (4, 5 e 6), o objetivo foi analisar como os dispêndios em P\&D tem efeito sobre os pedidos totais de patentes depositados no INPI, no mesmo período (2000 a 2011).

Os modelos seguiram a mesma técnica de estimação dos modelos 1,2 e 3 , sendo que o efeito foi analisado sobre a nova variável dependente (pedidos totais de patentes). Todas as estimações nos modelos 4, 5 e 6 tiveram coeficientes positivos, como esperado, e todos os resultados estatisticamente significantes, mostrando a importância desses dispêndios para a inovação medida por meio de depósitos de pedidos de patentes. Os resultados são mostrados na Tabela 3.

Tabela 3

Resultado do Impacto da P\&D nas Patentes (2000-2011)

\begin{tabular}{|c|c|c|c|}
\hline & Modelo 4 & Modelo 5 & Modelo 6 \\
\cline { 2 - 4 } & OLS1 & OLS2 & FD \\
\hline Coeficien & 0.4720542 & 0.0000119 & 0.5255711 \\
\hline p-valor & {$[0.000]$} & {$[0.000]$} & {$[0.006]$} \\
\hline
\end{tabular}

Fonte: Elaboração própria.

Testando uma hipótese de Random-Walk dos dados em P\&D, os resultados da Tabela 4 mostram um coeficiente positivo e um p-valor altamente significante. Portanto, dispêndios em P\&D se comportam como um passeio aleatório, ou seja, o melhor previsor para dispêndio em pesquisa e desenvolvimento, num determinado ano, é o gasto em P\&D no ano anterior.

\section{Tabela 4}

Resultado do Random-Walk (2000-2011)

\begin{tabular}{|c|c|c|c|}
\hline & Modelo 7 & - & - \\
\hline & OLS & - & - \\
\hline Coeficiente & 1,13882 & - & - \\
\hline p-valor & {$[0.000]$} & - & - \\
\hline
\end{tabular}

Pesquisas semelhantes na área foram de Silva et al (2013) que estimou o impacto dos determinantes dos gastos em P\&D para os países da OCDE entre 1990-2006 e a proxy utilizada também trouxe coeficientes positivos para o crescimento dos países. Outro trabalho que analisou os determinantes foi de Jensen et al (2004) com dados da ANPEI entre 1994-1998 e a pesquisa de Correia e Moita (2011), todos mostraram que há efeito positivo nos gastos e investimentos em inovação no desenvolvimento tecnológico do país, como foi mostrado neste trabalho. 


\section{CONSIDERAÇÕES FINAIS}

O panorama dos dispêndios públicos e privados em P\&D no Brasil, destinado como primeiro objetivo deste artigo, foi avaliado na seção 3, por meio de gráficos principais das séries estatísticas disponíveis no MCTI, mostrando que há uma política de dispêndios voltada para inovação, em consonância com as constatações de Mendes, Oliveira \& Pinheiro (2013). As séries de dados confirmam um comportamento crescente dos dispêndios em P\&D no Brasil, revelando ser uma estratégia de crescimento econômico e desenvolvimento tecnológico.

No segundo objetivo, foi avaliado se essa política tem surtido efeito em forma de incremento no PIB nacional e na proxy de inovação utilizada, total de pedidos de patentes no INPI. As séries analisadas mostram a evolução agregada dos dispêndios com P\&D para todos os anos analisados. Os resultados das estimações dos sete modelos propostos confirmam o efeito positivo dos dispêndios públicos e privados no crescimento do PIB e no aumento da quantidade de patentes depositadas, confirmando a importância desses dispêndios para o desenvolvimento tecnológico e econômico do Brasil. Além disso, no teste de comportamento Random-Walk dos gastos em pesquisa e desenvolvimento, foi possível concluir que o melhor previsor para tais dispêndios, num determinado ano, é o gasto em P\&D no ano anterior.

As evidencias empíricas mostram uma tendência neoschumpeteriana, que é uma posição adotada pela maioria dos países na atualidade. Mostrando que o Estado pode sim intervir no processo de inovação para ajustar as falhas de mercado, considerando que o mercado por si só não consegue fazer essa regulação. E os dados mostram que essa intervenção em política de ciência e tecnologia, traz efeito marginal positivo nos pedidos de patentes e no indicador de crescimento PIB.

Esta pesquisa necessita de continuidade, pois a inovação e seus dispêndios tem comportamento aleatório e mudam conforme as mudanças no mundo e nas políticas públicas. Outros aspectos devem ser analisados, como os dispêndios e seus impactos por setores e uma análise mais microeconômica da firma e seus investimentos em P\&D. Essas são limitações do presente trabalho e sugestões de incremento e novas pesquisas.

Revista de Administração e Inovação, São Paulo, v. 12, n.3 p. 268-286, jul./set. 2015. 


\section{REFERENCIAS}

Arundel, A., \& Kabla, I. (1998). What percentage of innovations are patented? empirical estimates for European firms. Research Policy, 27, pp. 127-141.

Associação Nacional de Pesquisa e Desenvolvimento das Empresas Inovadoras - ANPEI. (06 de setembro de 2014). Fonte: http://www.anpei.org.br/

BRASIL. (10 de janeiro de 2002). Código Civil - Lei $n^{o} 10.406$, de 10 de janeiro de 2002. Fonte: http://www.planalto.gov.br/ccivil_03/leis/2002/110406.htm

BRASIL. (02 de dezembro de 2004). Lei da Inovação - Lei $n^{o}$ 10.973, de 2 de dezembro 2004. Fonte: http://www.planalto.gov.br/ccivil_03/_ato2004-2006/2004/lei/110.973.htm

BRASIL. (21 de novembro de 2005). Lei do Bem - Lei $n^{o} 11.196$, de 21 de novembro de 2005. Fonte: http://www.planalto.gov.br/ccivil_03/_ato2004-2006/2005/lei/111196.htm

Correia, E., Moita, R. (2011). Gasto em P\&D e poder de mercado: teoria e evidência para o Brasil. Pesquisa e Planejamento Econômico. Brasília/IPEA.

Dosi, G., Freeman, C., \& Fabiani, S. (1994). The process of economic development: introducing some stylized facts and theories on technologies, firms and institutions. Industrial and Corporate Change, 3, pp. 1-45.

Griliches, Z. (1990). Patent statistics as economic indicators: a survey. Journal of Economic Literature, 29.

Gujarati, D. N. (2000). Econometria Básica. São Paula: Makron Books.

Hall, B. H., Helmers, C., Rogers, M., \& Sena, V. (April de 2012). The Choice between Formal and Informal Intellectual Property: A Literature Review. The National Bureau of Economic Research.

Hanel, P. (2008). The use of intellectual property rigths and innovation by manufactoring firms in Canada. Economics of Innovation and New Tecnology, 17, pp. 285-309.

Hayashi, F. (2000). Econometrics. Princeton: Princeton University Press.

Instituto Nacional de Propriedade Industrial - INPI. (28 de dezembro de 2012). Fonte: http://www.inpi.gov.br/portal/ 
Jensen, J., Menezes-Filho, N., Sbragia, R. (2004). Os Determinantes dos Gastos em P\&D no Brasil: Uma Análise com Dados em Painel. Estudos Econômicos, São Paulo.

Levin, R. C., Klevorick, A. K., Nelson, R. R., \& Winter, S. G. (1987). Appropriating the Returns from Industrial Research and Development. Brookings Papers on Economic Activity, 3, pp. 783-831.

Mendes, D. R. (14 de março de 2014). A Função Social da Propriedade Intelectual. Dissertação de Mestrado, 106. Brasília, DF, Brasil: Univesridade Católica de Brasília.

Mendes, D. R., Oliveira, M. A., \& Pinheiro, A. A. (2013). Política Nacional de Ciência, Tecnologia e Inovação: Avaliação do Marco Regulatório e seus Impactos nos Indicadores de Inovação. Revista de Empreendedorismo e Gestão de Pequenas Empresas, pp. 22-46.

Ministério da Ciência, Tecnologia e Inovação - MCTI. (06 de setembro de 2014). Fonte: http://www.mcti.gov.br/

Organização para a Cooperação e Desenvolvimento Econômico - OCDE. (2005). Manual de Oslo Proposta de Diretrizes para Coleta e Interpretação de Dados sobre Inovação. Oslo: OCDE.

Pearson, K. (1905). The Problem of the Random Walk. Nature, 72, p. 294.

Silva, M. S., Silva, E. H., Leal, P. Q. (2013) Determinantes de gastos em P\&D no âmbito da OCDE: uma abordagem neoschumpeteriana. ANPEC - XVI Encontro de Economia da Região Sul - ANPEC SUL 2013.

Woodridge, J. (2001). Econometric Analysis of Cross-Section and Panel Data. MIT Press, pp. 279291. 


\title{
ECONOMETRIC ANALYSIS OF EXPENDITURE ON RESEARCH AND DEVELOPMENT (R \& D) IN BRAZIL
}

\begin{abstract}
This research aimed to examine the outlook for spending on R\&D in Brazil and, more specifically, to evaluate the impact of these expenditures on national patent applications, and the impact on Gross Domestic Product (GDP) of the country. The analyzed series show the evolution aggregate of expenditures on $\mathrm{R} \& \mathrm{D}$ for the period analyzed. When disaggregated by major region, the data show that the Southeast and the South stand out in the application and granting of patents by the National Intellectual Property Institute (INPI). The estimation results of the seven proposed econometric models confirm the importance of public and private expenditures on GDP growth and increasing the amount of patents in the INPI. Another result of the estimations of this study demonstrate that such expenditures have behavior Random-Walk.
\end{abstract}

Keywords: Innovation; R \& D; Patents; Econometrics; Random-Walk.

JEL: O34 (Technological Change; Research and Development - Intellectual Property Rights: National and International Issues); K11 (Law and Economics - Property Law).

Data do recebimento do artigo: 10/10/2014

Data do aceite de publicação: 15/07/2015

Revista de Administração e Inovação, São Paulo, v. 12, n.3 p. 268-286, jul./set. 2015. 